\title{
Development of Resonant Density Meter and Its Application in Tailings Backfilling
}

\author{
Xiaozhou Cheng $\mathbb{D}^{1,2}$ \\ ${ }^{1}$ China University of Mining and Technology (Xuzhou), No. 1 Jinshan East Road, Quanshan District, Xuzhou City, \\ Jiangsu 221008, China \\ ${ }^{2}$ Sinosteel Maanshan General Institute of Mining Research Co., Ltd.,, No. 666, Xitang Road, Economic Development Zone, \\ Ma'anshan City, Anhui 243000, China \\ Correspondence should be addressed to Xiaozhou Cheng; cxz3005@163.com
}

Received 16 April 2021; Accepted 21 June 2021; Published 29 June 2021

Academic Editor: Lijie Guo

Copyright () 2021 Xiaozhou Cheng. This is an open access article distributed under the Creative Commons Attribution License, which permits unrestricted use, distribution, and reproduction in any medium, provided the original work is properly cited.

\begin{abstract}
To solve the problems of low measurement accuracy, poor safety, and stability of the traditional pipeline liquid density meter, a MIMR-XZ6 pipeline liquid density meter was designed based on the vibration mathematical model of fluid flowing through the pipeline. The pipeline liquid densitometer mainly consisted of a vibration tube for the liquid passing by, a distributed inductance encircled around the inner wall of the vibration tube, a resistor, and a capacitor, respectively, connected to both ends of the inductance, and the inductor, resistor, and capacitor formed the RLC series resonant circuit; an excitation signal source which could generate an alternating current (AC) voltage signal in different frequencies was applied to both ends of the RLC series resonant circuit, and the $\mathrm{AC}$ voltage signal was connected to the series branch formed by the inductance and the capacitor to capture the electrical signals. In view of the practical application of this liquid pipe densitometer in tailings backfilling, the installation method of the liquid pipe densitometer is flexible, and the slurry flows in a fluent and stable manner, meeting the measuring requirement of the resonant concentration analyzer. The MIMR-XZ6 pipeline liquid densitometer was used for online detection of ore pulp density, and the precision of this densitometer met the needs of industrial applications.
\end{abstract}

\section{Introduction}

The medium measured by the concentration density was made up of a mixture of mineral slurry and water. The flow rate of ore pulp should not stay too slow in the whole mineral processing to avoid precipitation. Therefore, the concentration of ore pulp was an important operational parameter of mineral processing. In the process of pipeline transportation and beneficiation, an overlow concentration of ore pulp would lead to lower production efficiency, but an overhigh concentration would bring production accidents such as pipe plugging. How to measure the concentration accurately for guiding the production was important.

The online measurement instrument for slurry concentration was mainly $\gamma$-ray densitometer at present. But the $\gamma$-ray had radiation hazards. The differential-pressure densitometer could be measured with good precision for static liquid, but the pressure change caused by the flow of the medium would interfere with the correlation between the pressure difference and the density of the medium and cause a decrease in the measurement accuracy. The ultrasonic densitometer was very sensitive to bubbles, vibration, and flow in the medium, and the drift of the measurement reference was serious. It needed constant calibration during the working process and is hard to measure stably and reliably for a long time. Therefore, it was particularly important to find a safe and accurate online densitometer for pipeline liquid. This research of pipeline liquid densitometer was proposed in the context.

Greenwood and Bamberger [1] have studied computercontrolled sensors that measure the density of liquids or slurries in real time and deployed them at a base in the United States to monitor the characteristics of the slurries during the transfer of radioactive waste. Sickels [2] proposed 
a device and method for determining the density and other characteristics of corrosive liquids (such as drilling mud). Using the relationship between the vibration frequency of the tuning fork and the density of the liquid between the walls of the fork, Tang et al. [3] proposed a tuning fork liquid density meter. Li and Cui [4] designed a new type of lowpower and high-precision ultrasonic liquid medium density meter using the measurement principle of ultrasonic time difference method and the high-speed time-to-digital conversion chip TDC-GP2. Li et al. [5] prioritized pure water as the working medium when conducting static pressure tests on the online vibrating tube densitometer to obtain correction coefficients to ensure measurement accuracy.

The pipe would vibrate at different frequencies when the different density fluid flowed through. Hence, to measure the frequency of vibration of pipes, the density of fluid would be detected, and the MIMR-XZ6 pipeline liquid densitometer was developed in this theory. This novel pipeline liquid has an allowable range of true error and provides a good technical guarantee for the efficient and safe production of tailings backfilling operations.

\section{The Mathematical Model of the Pipeline Liquid Density Meter}

The mathematical model of vibration when the fluid flows through the pipeline is shown in equation (1). The measuring tube of the pipeline liquid density meter is shown in Figure 1. The waveforms of three different vibration modes on the tube length along the vertical and horizontal directions are shown in Figure 2 [6-8].

$$
E \times I \frac{\partial^{4} y(x, t)}{\partial x^{4}}+\left(\rho_{w} S_{i}+\rho_{t} S_{t}\right) \times \frac{\partial^{2} y(x, t)}{\partial t^{2}}=0 .
$$

In equation (1), $E$ is the elastic modulus of the measuring tube; $I$ is the second moment of the measuring tube to the central axis; $S_{i}$ and $S_{t}$ were, respectively, the cross-sectional areas of the tube occupied by the liquid in the tube through which the fluid flows and the cross-sectional area of the measuring tube; $\rho_{w}$ and $\rho_{t}$ were, respectively, the density of the liquid to be measured in the tube and the density of the measuring tube. Vibrating tubes were made of high-elastic alloy $42 \mathrm{CrMo}$ chrome-molybdenum alloy steel with a low hysteresis effect in the actual manufacturing process.

Solving equation (1) under a given boundary gave the vibration frequency of the horizontal measuring tube as follows $[6-8]$ :

$$
f=\frac{\lambda^{2} \sqrt{E \times I /\left(\rho_{w} S_{i}+\rho_{t} S_{t}\right)}}{2 \pi L^{2}},
$$

where $\lambda$ is the constant associated with the boundary conditions and the vibration mode of the measuring tube and $L$ is the length in the axial direction of the measuring tube.

The solution of density would be solved as follows [6-8]:

$$
\rho_{w}=\frac{\lambda^{4} E \times I / 4 \pi L^{4} f^{2}-\rho_{t} S_{t}}{S_{i}} .
$$

\section{The Realization of Online Measurement Principle of the Pipeline Liquid Density Meter}

The liquid density meter was mainly composed of a cavity vibration sensor, and its working principle is as shown in Figure 3 . When the liquid flowed through the vibrating tube, the cavity vibrating sensor surrounded the vibrating tube through which the fluid flowed, and the inner and outer walls of the vibrating tube body were surrounded by an inductive coil, respectively, connected to the two lead ends of the inductive coil. Inductor, resistor, and capacitor formed an RLC series resonant circuit; the excitation signal source generated an $\mathrm{AC}$ voltage signal of different frequencies. The AC voltage is applied to both ends of the RLC series resonant circuit as an excitation signal. The AC voltage was connected to the series branch formed by the inductor coil and the capacitor, to capture the electrical signal at both ends of the series branch. When different fluids flowed through the vibrating tube, vibrations of different frequencies occurred. Resonance will appear when the frequency of the signal generated by the excitation signal source coincides with the frequency of the vibrating tube. The mixer outputted different harmonics between the resonant frequency and the signal frequency of the external excitation signal source. The density of the fluid was obtained by converting the frequency difference signal into an electrical signal through a detector, a filter, and an identifier. According to the above principle, we developed the pipe liquid density meter MIMR-XZ6 which is shown in Figure 4. The relationship between the frequency of vibration and the density of the liquid measured by the experiment is shown in Table 1 .

It can be seen from Table 1 that the density of liquid measured by the developed liquid density meter had a smaller error than the true value, which was a reason for the range of error.

\section{The Application of the Pipeline Liquid Density Meter in Tailings Backfilling}

4.1. The Performance Analysis of Graded Tailings Backfilling Slurry. Cement-grade tailings backfilling slurry was the material that was mixed artificially by solid-liquid two-phase concrete. Its strength was affected by the sedimentation properties of the slurry previous solidification. The settling velocity and direction of filling material solid particles with different particle sizes were disordered in the mixing region. The mutual interference between the particles reduced the sedimentation speed of the particles, which resulted in the stickiness between the materials of the concrete mixture in the slurry. The force of gathering was not enough to resist the sinking of the coarse aggregate. The concrete mixture components were separated from each other, resulting in uneven internal composition and structure. The more the water was, the more the particle size distribution was unreasonable. The serious separation phenomenon in the slurry resulted in a negative impact on the strength of the filling [9-12]. 


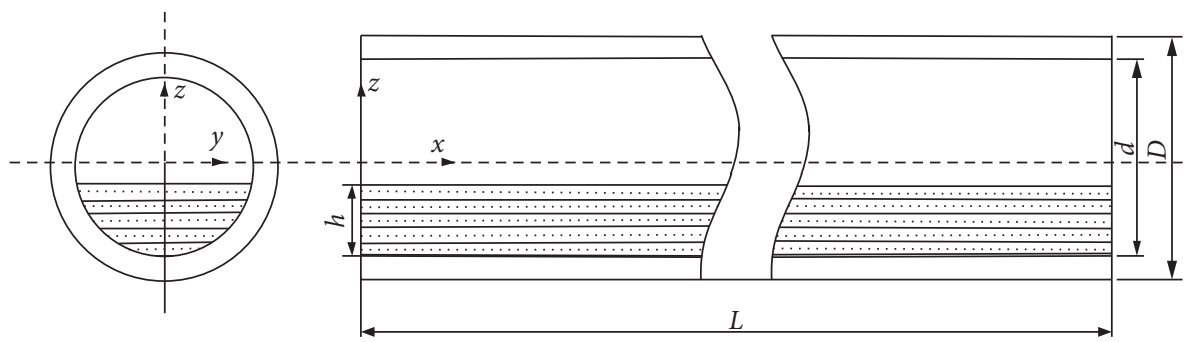

FIgURE 1: Schematic diagram of a measuring tube flowing through a liquid.

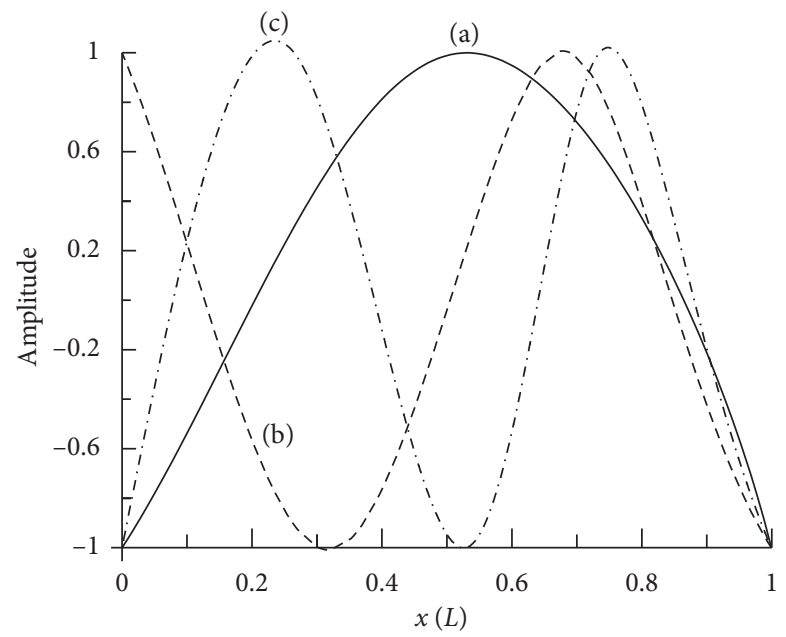

FIGURE 2: Waveforms of three different modes of vibration along with the vertical and horizontal directions over the length of the tube.

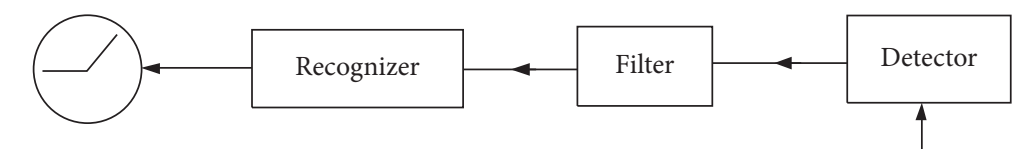

Density display

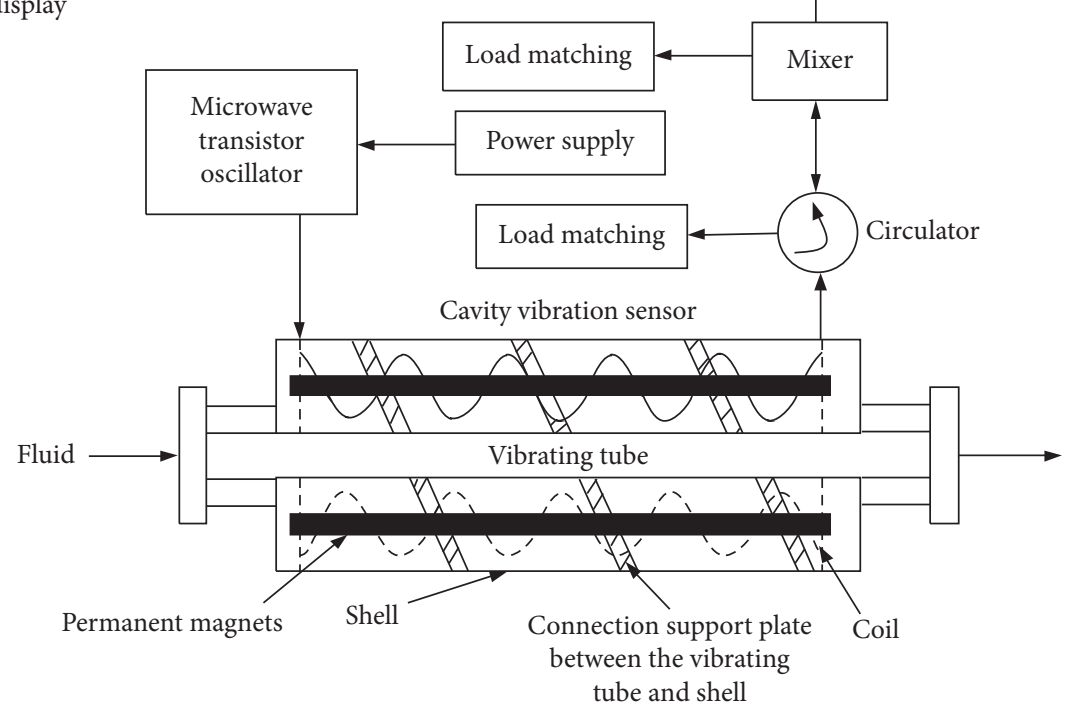

FIgURE 3: Liquid density meter online measurement principle realization diagram.

The sedimentation experiment was carried out on the filling slurry with different concentration ratios. The variation of the sedimentation performance of the slurry with the concentration of the mixture was analyzed. The slurry was poured into the container and the mixture was stirred quickly. Then let it settle naturally during the experiment. The solid particles in the slurry sank gradually under the action of gravity. The upper clear water precipitated gradually. 


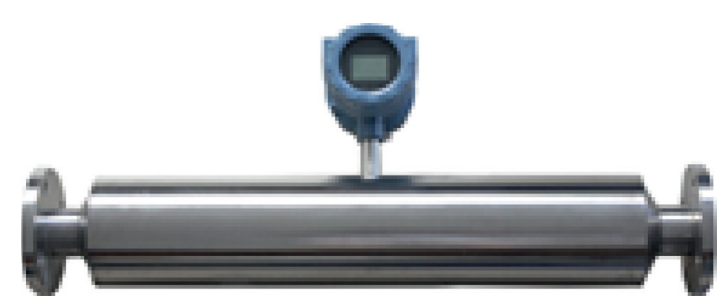

FIgURE 4: The real developed liquid density meter online measurement.

TABLE 1: The relationship between the frequency of vibration and the density of the liquid.

\begin{tabular}{|c|c|c|c|c|c|}
\hline \multirow{2}{*}{ No. } & \multirow{2}{*}{ Frequency of vibration $(\mathrm{Hz})$} & \multirow{2}{*}{ The temperature of the liquid $\left({ }^{\circ} \mathrm{C}\right)$} & \multicolumn{2}{|c|}{ Density $(\mathrm{kg} / \mathrm{m})$} & \multirow{2}{*}{ Error } \\
\hline & & & True value & Measurement & \\
\hline 1 & 744.15 & 22.8 & 998 & 998 & 0.00 \\
\hline 2 & 683.45 & 21.5 & 1887 & 1886 & -0.001 \\
\hline 3 & 754.78 & 24.6 & 998 & 998 & 0.00 \\
\hline 4 & 748.67 & 23.5 & 998 & 997 & -0.001 \\
\hline 5 & $739 . .80$ & 22.4 & 998 & 998 & 0.00 \\
\hline 6 & 733.72 & 21.4 & 998 & 998 & 0.00 \\
\hline 7 & 836.65 & 22.3 & 1.00 & 1.00 & 0.00 \\
\hline
\end{tabular}

The sedimentation performance of the slurry was directly reflected by observing the change of the height of the clear water layer. The sedimentation experiment resulted in various types of lime sand slurry with the concentration of $58 \%, 65 \%$, and $72 \%$ and the test values of the settlement experiment are shown in Table 2. It can be seen from Table 2 that the sedimentation performance of the graded tailings had a great influence on the physical properties of the pack. The slurry was usually saturated at the initial stage after the agitation. The capillary pressure in the slurry and the solid particles are naturally compacted by the weight of the solid particles, resulting in a decrease in the volume of the slurry and dehydration.

The specific gravity, bulk density, grain size composition, and porosity of cement-grade tailings backfilling slurry influenced sedimentation directly. Its physical and chemical properties were different, resulting in its different performance. The bulk density and porosity of the slurry were larger. The larger the bulk density and porosity of the slurry, the fluffier the structure, the larger the compression coefficient, and the smaller the strength. The liquid phase water was discharged with time after filling in the goaf. The solid phase filling material particles shrink gradually under their gravity. Porosity decreased correspondingly and the bulk density of the slurry increased gradually. The structure tended to be dense and the strength was further improved [13-16].

Figure 5 shows the effect of the ratio of different coarse and fine sands and the concentration of the slurry on the strength of the filled test block when the ratio of lime to sand was $1: 7$. It could be seen from Figure 5 the ratio of the thickness of the coarse sand and the concentration of the slurry to the strength of the packed block. It did not exhibit regular changes. When the ratio of coarse to fine sand was $1: 3.5$ and the slurry concentration was $64.93 \%$, the packing block had a good strength of $3.47 \mathrm{MPa}$.
4.2. Density Meter Installation. The resonant density meter adopts a pipeline design and flange connection, and it is easy to install. In this application, the density meter was installed at the bottom of the tailings sand tank. The density meter was used as a part of the tailings conveying pipeline. The density of the tailings can be measured when the tailings flow through the density meter. The installation position is shown in Figure 6.

\subsection{The Application of the Pipeline Liquid Density Meter in} Tailings Backfilling Process. The 10\% overflow from the top of the cyclone and $25 \%$ overflow from high sulfur tailings, wastewater, and slurry mixed with the fine sand pool entered the thickener together. The fine mortar from the bottom of the thickener was driven into the fine sand pool by a ceramic plunger pump. The fine mortar coming out from the bottom of the fine sand pool was driven into the sand pool by the ceramic plunger pump after passing through the intermediate buffer pool. The slurry prepared according to a certain ratio of coarse sand coming out from the bottom of the fine sand pool through the intermediate buffer pool then entered the double screw mixer. The liquid pipe density meter monitored the slurry concentration. The cement was designed according to the optimal proportion of the sandsand ratio. After being fed by the double-tube screw feeder, it was metered by a spiral electronic scale and sent to a highspeed activated double-helical mixer for uniform mixing. It was a highly efficient activated slurry for filling the mining bed. The system process of the specific tailings backfilling is shown in Figure 6.

The parameters of the system process in the tailings backfilling process were controlled by a computer. The control interface screenshot is shown in Figure 7. The ratio of coarse and fine sand of slurry during tailings backfilling operation, the concentration of the slurry, the 
TABLE 2: The test values of the settlement experiment.

\begin{tabular}{|c|c|c|c|c|c|}
\hline $\begin{array}{l}\text { The ratio of } \\
\text { ash and sand }\end{array}$ & $\begin{array}{c}\text { The initial } \\
\text { concentration (\%) }\end{array}$ & $\begin{array}{l}\text { The slurry weight after } \\
\text { sedimentation }\left(\mathrm{kg} / \mathrm{m}^{3}\right)\end{array}$ & $\begin{array}{c}\text { The concentration of } \\
\text { slurry after sedimentation } \\
(\%)\end{array}$ & $\begin{array}{c}\text { The volume ratio of } \\
\text { settling water to } \\
\text { slurry (\%) }\end{array}$ & $\begin{array}{l}\text { The volume ratio of } \\
\text { settled water to total } \\
\text { water (\%) }\end{array}$ \\
\hline \multirow{3}{*}{ Cement free } & 58 & 2.1 & 77.0 & 30.0 & 38.0 \\
\hline & 65 & 2.1 & 78.0 & 18.0 & 28.0 \\
\hline & 72 & 2.1 & 78.6 & 7.0 & 13.6 \\
\hline \multirow{3}{*}{$1: 4$} & 58 & 2.1 & 77.0 & 29.0 & 37.3 \\
\hline & 65 & 2.1 & 78.0 & 18.0 & 28.0 \\
\hline & 72 & 2.1 & 78.0 & 6.5 & 12.0 \\
\hline \multirow{3}{*}{$1: 6$} & 58 & 2.1 & 76.7 & 27.0 & 35.0 \\
\hline & 65 & 2.1 & 77.0 & 15.0 & 23.9 \\
\hline & 72 & 2.1 & 78.0 & 5.7 & 10.8 \\
\hline \multirow{3}{*}{$1: 8$} & 58 & 2.1 & 76.0 & 25.0 & 33.8 \\
\hline & 65 & 2.1 & 77.0 & 15.0 & 23.8 \\
\hline & 72 & 2.1 & 77.7 & 4.6 & 8.9 \\
\hline
\end{tabular}

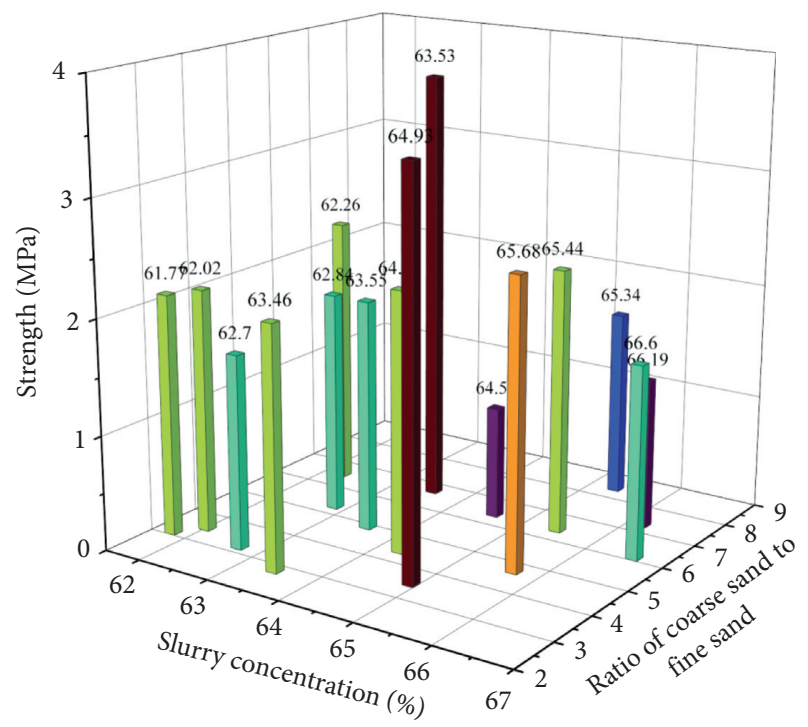

FiguRE 5: The effect of different ratios of coarse and fine sand and the concentration of slurry on the strength of the filled test block when the ratio of lime to sand is $1: 7$. Notes. The test block has a volume of $353.39 \mathrm{~cm}^{3}$ and a cross-sectional area of $49.98 \mathrm{~cm}^{2}$.

level of the sand pool, the hydration flow rate and the cement dosage every day, and the total amount of sand were learned through the online control system. One of the important control parameters was the concentration of the slurry which was measured by the liquid pipe density meter. The concentration of the slurry is shown in Figure 8.

It was seen from Figure 8, during the operation, the slurry concentration changed substantially with time at a concentration of $1650 \mathrm{~kg} / \mathrm{m}^{3}$. During the operation, if the concentration changed, the operator adjusted other process parameters opportunely. If we want to control the proportion of coarse sand, choose the appropriate ratio of sand and cement to meet the filing requirements of the mining method. Finally, a suitable concentration of filler slurry was selected to ensure that the tailings mixture material improved the structural strength of the deposit filling area while maintaining fluidity [17-20]. 


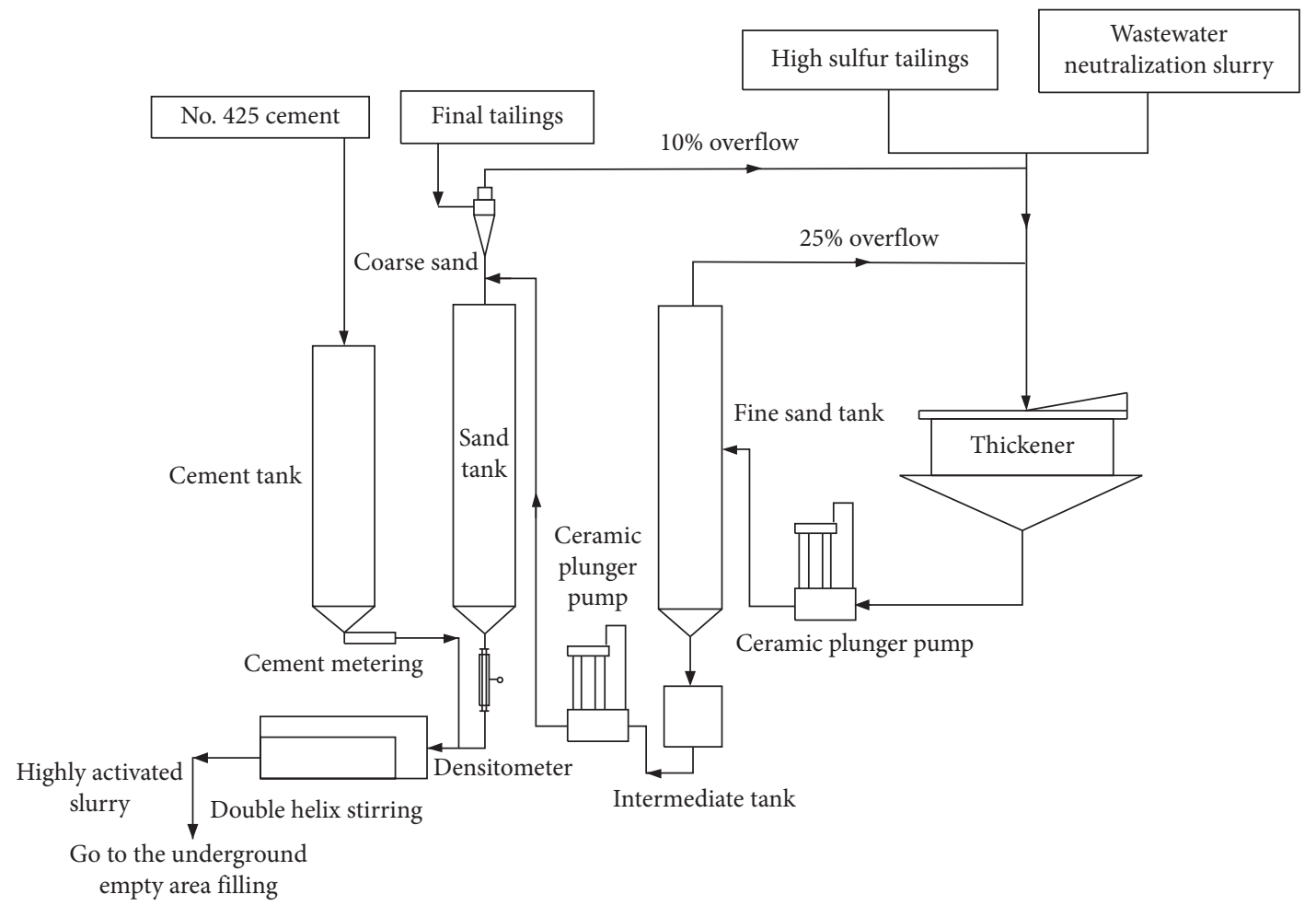

FIgURE 6: Tailings backfilling system process.

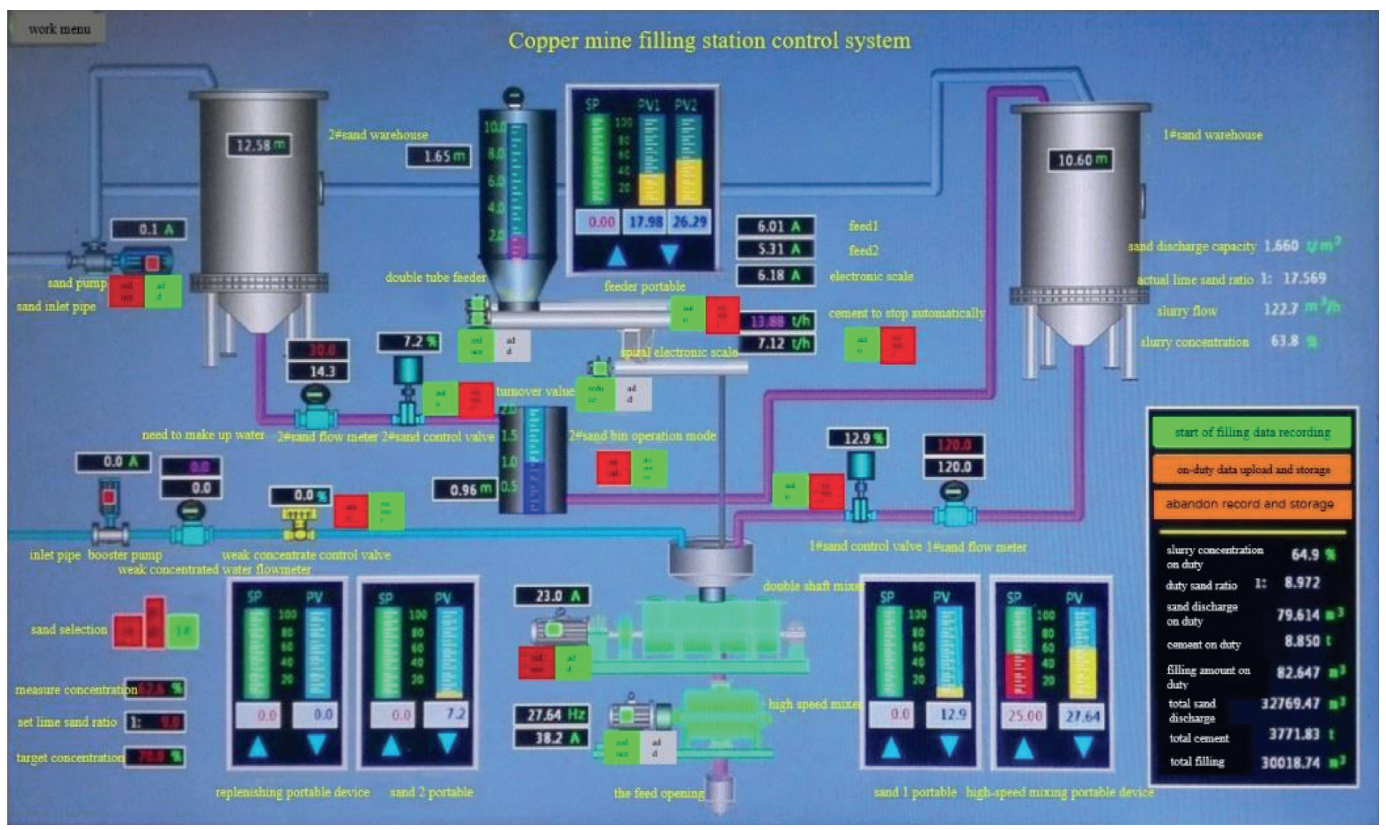

FIGURE 7: Screenshot of system process parameters for tailings backfilling. 


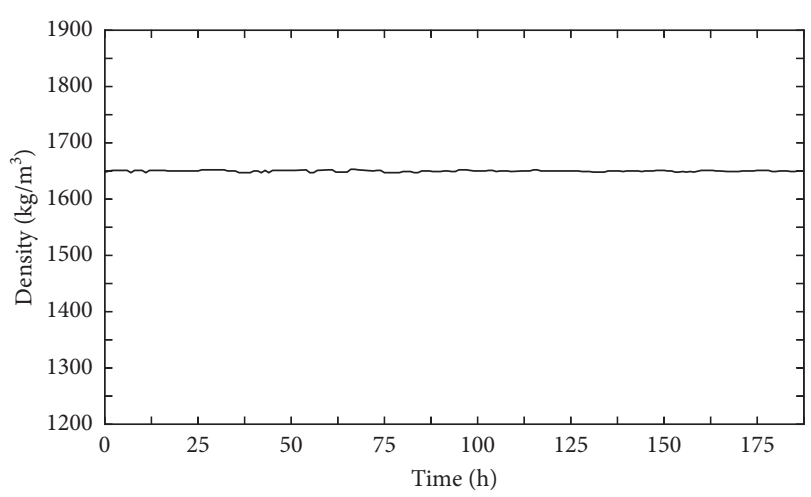

FIgURE 8: Relationship between slurry concentrations monitored over time during operation.

\section{Conclusions}

Starting from the mathematical model of the liquid pipeline density meter, this paper introduces its detection principle and its realization method. From the actual application information of the developed liquid pipeline density meter in tailings backfilling, the installation method of the liquid pipeline density meter is flexible and the slurry flows in a fluent and stable manner, meeting the measurement requirements of the resonant concentration analyzer.

The results from the on-site sampling and according showed that the deviation of the liquid pipeline densitometer measurement is about $1 \%$, the deviation of the concentration measurement is about $3 \%$, and the deviation value was stable and stayed in the range of allowable error in the whole process. The recorded data of ore pulp concentration and variation tendency had a certain relationship with the actual conditions in the production process, which provided specific technical support for the efficient and safe production of tailings backfilling operations.

\section{Data Availability}

Experimental data come from on-site sampling.

\section{Conflicts of Interest}

The author declares that there are have no conflicts of interest.

\section{References}

[1] M. S. Greenwood and J. A. Bamberger, "Ultrasonic sensor to measure the density of a liquid or slurry during pipeline transport," Ultrasonics, vol. 40, no. 1-8, pp. 413-417, 2002.

[2] R. E. Sickels, "Measuring the properties of a corrosive liquid," Journal of Politics \& Government Week, vol. 7, no. 4, pp. 3085-3091, 2015.

[3] T. Tang, H. Yu, Q. Chen et al., "Design of tuning fork liquid density meter," Journal of Yangtze University Natural Science Edition: Science and Engineering, vol. 13, no. 22, pp. 14-18, 2016.

[4] K. Li and Y. Cui, "New ultrasonic liquid density meter based on time difference method and TDC-GP2," Instrument Technique and Sensor, vol. 431, no. 12, pp. 123-126, 2018.
[5] Z. Li, C. Han, and Z. Wang, "Analysis of static pressure correction test of online vibration tube liquid densitometer," Oil-Gasfield Surface Engineering, vol. 39, no. 6, pp. 29-32, 2020.

[6] I. Mnassri and A. E. Baroudi, "Vibrational frequency analysis of finite elastic tube filled with compressible viscous fluid," Acta Mechanica Solida Sinica, vol. 30, no. 4, pp. 435-444, 2017.

[7] J. A. S. Hidalgo, A. L. Gama, and R. M. Moreira, "Natural vibration frequencies of horizontal tubes partially filled with liquid," Journal of Sound and Vibration, vol. 408, pp. 31-42, 2017.

[8] A. El Baroudi, F. Razafimahery, and L. Rakotomanana, "Fluidstructure interaction within three-dimensional models of an idealized arterial wall," International Journal of Engineering Science, vol. 84, pp. 113-126, 2014.

[9] X. Peng and X. Yang, "Phenomenon and mechanism of settlement process of tailings backfill slurry," China Mining Magazine, vol. 26, no. 4, pp. 126-130, 2017.

[10] X. Chen, X. Yang, L. Guo et al., "Experimental study on the determination of cement content in cemented tailings backfill," Nonferrous Metals Engineering, vol. 8, no. 6, pp. 73-78, 2018.

[11] S. Zhu, Y. Hou, L. Chen et al., "Settlement performance and influencing factors of total tailings," Chinese Journal of Underground Space and Engineering, vol. 13, no. 4, pp. 931-937, 2017.

[12] S. Wang, S. Su, and F.-1. Wang, "Analysis of strength regularity of high concentration tailings cemented backfill," Bulletin of the Chinese Ceramic Society, vol. 38, no. 3, pp. 847-852, 2019.

[13] H. Hou, C. Li, S. Wang et al., "Settling velocity variation of mud layer and particle settling characteristics in thickening of tailings," Journal of Central South University, vol. 50, no. 6, pp. 1428-1436, 2019.

[14] R. Zhou, "Application of graded tailings cement filling in Wushan copper mine," Nonferrous Metals, vol. 62, no. 3, pp. 1-2, 2010.

[15] J. Gao, "Application of large-scale downward cementation filling mining method in Jinchuan nickel mine," Mining Engineering, vol. 59, pp. 136-139, 2005.

[16] Y. Teng, J. Ma, and J. Chen, "Study and application of tailings cementing backfilling technique in Xulou iron mine," Modern Mining, vol. 33, no. 2, pp. 65-68, 2017.

[17] P. M. Dighe, "Design simulation studies of pipe mounted boron concentration meter," Annals of Nuclear Energy, vol. 134, pp. 414-423, 2019.

[18] P. Wei and J. Wang, "Design of ultrasonic pulp concentration meter based on STM32," Industrial Control Computer, vol. 30, pp. 133-134, 2017.

[19] D. Gao, "Development of an intelligent non-contact ultrasonic densitometer," Instrumentaion, vol. 23, pp. 1-4, 2016.

[20] H. Zhao, J. Zhao, and C. Zhou, "Design of an weighting method concentration meter," China Mining Magazine, vol. 25, pp. 473-475, 2016. 